\title{
Portal vein thrombosis: an overview of current treatment options
}

\author{
A. Galante, A. De Gottardi \\ Department of Gastroenterology and Hepatology, Ente Ospedaliero Cantonale, Università della Svizzera Italiana, Lugano, Switzerland.
}

\begin{abstract}
Portal vein thrombosis (PVT) is a splanchnic vascular disorder characterised by a recent or chronic thrombotic occlusion of the portal venous system. Its aetiology is miscellaneous, and its management is demanding since PVT can play a critical role as far as morbidity and mortality are concerned. Indeed, PVT can develop as a complication of portal hypertension (PH), in association or not with advanced chronic liver disease, and aggravate its clinical consequences such as variceal bleeding and ascites. Furthermore, a diagnosis of PVT in a non-cirrhotic context can potentially reveal a previously unknown hypercoagulable condition, requiring further diagnostic steps and specific treatment in addition to anticoagulation.

In addition to established therapeutic approaches, new strategies, including newer pharmacological treatments and interdisciplinary invasive procedures, gain more attention and have been increasingly introduced into clinical practice. This review aims at discussing the current knowledge in terms of treatment options for PVT. (Acta gastroenterol. belg., 2021, 84, 327-332)
\end{abstract}

Keywords : Portal vein thrombosis, portal hypertension, cirrhosis, anticoagulation, transjugular intrahepatic portosystemic shunt.

Abbreviations : ACLD, advanced chronic liver disease; CRR, complete radiographic resolution; DOAC, direct oral anticoagulant; HCC, hepatocellular carcinoma; IBD, inflammatory bowel disease; INR, international normalized ratio ; JAK-2, Janus Kinase-2 ; LMWH, low-molecular-weight heparin; LT, liver transplantation; NASH, non-alcoholic steatohepatitis; PT, portal hypertension; PV, portal vein; PVT, portal vein thrombosis; SMV, superior mesenteric veins ; TIPS, transjugular intrahepatic portosystemic shunt; UFH, unfractionated heparin; VKA, vitamin $\mathrm{K}$ antagonist; VWF, von Willebrand factor

\section{Introduction}

Portal vein thrombosis (PVT) is a challenging clinical condition, currently representing the most frequent complication involving the hepatic vascular system. It is defined by thrombotic occlusion of the intra and/or extrahepatic portal venous system $(1,2)$. It may involve the portal vein (PV) trunk and its main branches and potentially extend to the splenic and superior mesenteric veins (SMV). PVT can result in a partial or complete obstruction to the portal venous blood flood, ranging from an asymptomatic diagnostic finding during abdominal imaging to a severe clinical condition characterised by the clinical consequences of portal hypertension (PH) (14).

Reduced portal blood flow, a hypercoagulable state and vascular endothelial injury can all play a role in the pathophysiology of PVT, which clinically shows up in two main potential scenarios : in the first scenario, that is more frequent, it evolves from a context of underlying advanced chronic liver disease (ACLD) such as cirrhosis, and is mainly due to hemostatic and hemodynamic alterations that are typical of cirrhosis itself or accompanies complications such as hepatocellular carcinoma (HCC) ; in the other scenario, PVT develops in the absence of underlying liver disease, mainly in clinical conditions characterised by inflammation and/or a hypercoagulable state $(1,2,5)$.

PVT is, therefore, a common complication in patients with cirrhosis, where its prevalence increases with the severity of the underlying liver disease, ranging from approximately $1 \%$ in patients with compensated cirrhosis to $8-25 \%$ in candidates for liver transplantation (LT) (6-8), with an incidence of $3.2 \%-4.1 \%$ one year after diagnosis in cirrhotic patients (1). Patients with both cirrhosis and hepatic carcinoma (HCC) have the highest PVT prevalence, reaching $40 \%$ of cases (9-10). With regard to the aetiology of underlying liver disorder, cirrhosis by non-alcoholic steatohepatitis (NASH) has been identified as an independent risk factor for PVT (11). However, whether PVT increases morbidity and mortality in the context of ACLD (12) or whether it merely represents a manifestation of disease progression (9), still remains a matter of debate and research.

On the other hand, non-cirrhotic PVT is a rare event in several different conditions, mostly due to an inflammatory intraabdominal process or a systemic hypercoagulable state, and it can implicate a considerable disease burden $(2,13)$. Antiphospholipid syndrome, myeloproliferative diseases, and prothrombin gene mutations account for the most common systemic conditions associated with PVT (13). Among less common risk factors for PVT, the hypercoagulable state of patients with inflammatory bowel disease (IBD) can favour venous thromboembolism in the splanchnic district as well (14). However, only a small proportion of patients with non-cirrhotic PVT develops long-term complications, and the survival rate after 5 years from diagnosis of a non-cirrhotic PVT is

\footnotetext{
Correspondence to: Andrea De Gottardi, Gastroenterology and Hepatology Department, Ente Ospedaliero Cantonale, Università della Svizzera Italiana, Via Pietro Capelli 1, 6962 Lugano, Switzerland. Email : Andrea.Degottardi@usi.ch

Submission date : 15/03/2021 Acceptance date : 22/03/2021
} 
Table 1. - Risk factors for developing portal vein thrombosis (PVT)

\begin{tabular}{|c|c|}
\hline Local/Abdominal & Systemic \\
\hline Cirrhosis & Congenital \\
\hline $\begin{array}{l}\text { - Portal hypertension } \\
\text { - PHCC } \\
\text { - PNASH } \\
\text { - PTIPS dysfunction } \\
\text { - PSurgical portosystemic shunt }\end{array}$ & $\begin{array}{l}\text { - PFactor V Leiden mutation } \\
\text { - PProtein C or S deficiency } \\
\text { - PFactor-II-(Prothrombin) Mutation } \\
\text { - PProtein C or S deficiency } \\
\text { - PAntithrombin deficiency }\end{array}$ \\
\hline Malignancy & Acquired \\
\hline $\begin{array}{l}\text { - PHCC, cholangiocarcinoma, pancreatic - Pcarcinoma } \\
\text { - POther cancer of abdominal organs }\end{array}$ & $\begin{array}{l}\text { - PMyeloproliferative disorders (JAK-2-Mutation) } \\
\text { - PAntiphospholipid syndrome } \\
\text { - PHyperhomocystinemia } \\
\text { - PParoxysmal nocturnal hemoglobinuria } \\
\text { - PPregnancy } \\
\text { - POral contraceptive use }\end{array}$ \\
\hline \multicolumn{2}{|l|}{ Inflammatory states } \\
\hline \multicolumn{2}{|l|}{$\begin{array}{l}\text { - PPancreatitis } \\
\text { - PCholecystitis } \\
\text { - PCholangitis } \\
\text { - PDiverticulitis } \\
\text { - PAppendicitis } \\
\text { - PInflammatory bowel disease }\end{array}$} \\
\hline \multicolumn{2}{|l|}{ Injury to the portal venous system } \\
\hline $\begin{array}{l}\text { - PPost abdominal surgery, including bariatric surgery, splenectomy } \\
\text { - PAbdominal trauma }\end{array}$ & \\
\hline
\end{tabular}

generally good, ranging from $70 \%$ to $96 \%$ and depending primarily on the underlying condition (15-18).

Patients may have multiple local and/or systemic factors favouring PVT development in a cirrhotic setting and without ACLD. A list of the most common risk factors for PVT is summarised in Table 1. However, considering the duration and clinical presentation of PVT, it is also useful, from the viewpoint of potential therapeutic approaches, to distinguish recent PVT, where thrombosis is detected for the first time in a previously perfused PV, possibly with its accompanying characteristic features on imaging findings (4), from chronic PVT, with typical clinical signs of portal hypertension and with portal cavernomatous transformation on cross-sectional imaging (2). Moreover, the classification includes asymptomatic and symptomatic PVT, defined mainly by the presence of ascites and/or signs of acute bowel ischemia in recent non-cirrhotic PVT or features of portal hypertension in chronic PVT $(1,2,19)$.

The optimal management of PVT is demanding. Indeed, due to its heterogeneity with respect to the aetiology and clinical context of its onset, PVT remains a clinical condition that is difficult to treat as the choice of treatment is complex and must often be tailored to the patient and the characteristics of thrombosis.

\section{The natural history of PVT : to treat or not to treat?}

The aim of the treatment of PVT is recanalisation. However, the therapeutic strategy must be adapted to the extension of the thrombus and the patient's characteristics. For instance, in ACLD, important alterations of the hemostatic system may lead to thrombotic events, as well as life-threatening hemorrhagic complications (20). Furthermore, in these patients, recanalisation of the
PV may occur spontaneously in up to $40 \%$ of patients. When there are no recanalisation predictors, patient identification for treatment is extremely demanding $(7,21)$. However, recanalisation rates remain higher with anti-thrombotic treatment (2).

The main indication to treat a recent PVT is to avoid developing a series of complications, which may differ in patients with or without preexisting ACLD. Patients with cirrhotic PVT may develop venous collaterals as an adaptive mechanism to bypass the obstacle (6) and may experience a potential aggravation of relevant $\mathrm{PH}$ related complications, such as gastrointestinal bleeding, ascites, hypersplenism and overt hepatic encephalopathy (HE) (5-6). In patients without pre-existing cirrhosis, the fast increase in portal pressure in the absence of available portosystemic collaterals can quickly lead to potentially life-threatening complications like intestinal infarction (20-60\% mortality), ascites and infections $(13,22)$.

Data about PVT natural history come mainly from retrospective cohort studies, and especially in patients with underlying cirrhosis, results are controversial. Most recent data show a positive impact of PVT recanalisation on morbidity due to PH-related events and general survival in patients with cirrhosis (23). However, there is no clear association between PVT and chronic liver disease progression into hepatic decompensation, while PVT usually seems to follow decompensation rather than initiate it (9). However, there is clearly the indication to maintain the main patent $\mathrm{PV}$ in cirrhotic patients who are liver transplant (LT) candidates. Indeed, a non-anatomic $\mathrm{PV}$ reconstruction at the time of LT surgery is technically inconvenient (24-25), and LT recipients with PVT show worse outcomes in terms of survival and post-transplant complications (26-27). 

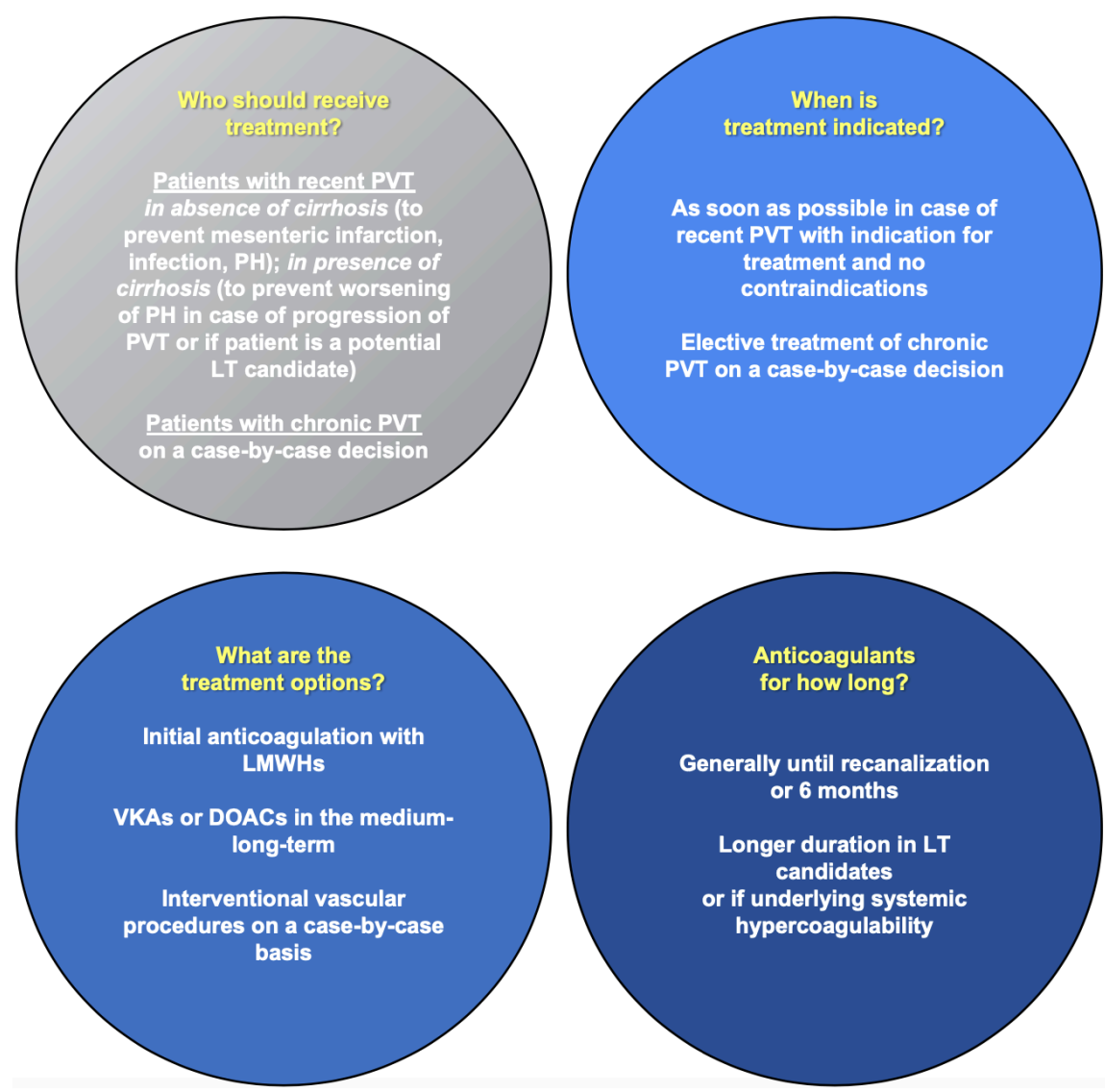

Figure 1: Current therapeutic options for portal vein thrombosis (PVT), a four-boxes schematic to consult before starting a treatment. Abbreviations: DOAC, direct oral anticoagulant; LMWH, low-molecular-weight heparin; LT, liver transplantation; $\mathrm{PH}$, portal hypertension ; PVT, portal vein thrombosis ; VKA, vitamin K antagonist.

In patients with non-cirrhotic PVT, when treatment is started quite early, the incidence of complications, especially mesenteric infarction, is very low, whereas up mortality to $60 \%$ is observed if no anticoagulant therapy is started early (13). Anticoagulant treatment is also intended to prevent the extension of the thrombotic process to the mesenteric veins (17) and to achieve a full recanalisation so as to avoid late complications of $\mathrm{PH}$ and portal cavernoma $(19,28)$.

\section{First-line treatment for PVT : anticoagulation}

The choice to start anticoagulation depends on the staging of PVT and its setting of development. Currently available anticoagulants for PVT treatment include heparins, vitamin $\mathrm{K}$ antagonists (VKA) and direct oral anticoagulants (DOACs).

Heparins - consisting of unfractionated heparin (UFH) and low-molecular-weight heparin (LMWH) - represent the mainstay of initial anticoagulation, although there are several limitations. Indeed, heparins need to be injected intravenously (UFH) or subcutaneously (LMWH) and can trigger bleeding complications, in particular in cirrhotic patients (29). The most frequent approach is to switch to oral anticoagulants after an initial treatment with LMWH.

VKAs, such as warfarin, acenocoumarol or phenprocoumon, are well-established oral anticoagulants with similar risk profiles of major bleeding events like heparins but require close monitoring of INR to achieve therapeutic ranges (30). In this context, DOACs, including direct factor Xa inhibitors and direct factor IIa inhibitors, are emerging as a convenient therapy option with similar safety and effectiveness compared to heparins and VKA. Their mechanism of action - inhibiting thrombin or FXa without the mediation of antithrombin or carboxylation - could be more favourable in patients with cirrhosis and PVT than traditional anticoagulants (31-34). Also, the use of DOACs does not need monitoring and reversal agents are already available. Therefore, their use in clinical practice for the treatment of non-cirrhotic PVT and PVT in compensated cirrhosis is widely increasing (29,3140), while a superior anticoagulant efficacy of DOACs versus traditional anticoagulants is still controversial $(31,41)$ and data in patients with more advanced stages of cirrhosis are lacking. 


\section{Anticoagulation in non-cirrhotic PVT}

In patients without an underlying ACLD, a prompt start of anticoagulation is essential to achieve recanalisation and avoid thrombus extension to the mesenteric and splanchnic veins, thus preventing intestinal ischemia and the development of $\mathrm{PH}$ and its related complications. Traditional anticoagulants like LMWH and VKAs are the first choice in current guidelines (1). Indeed, the benefit-risk ratio between anticoagulation and bleeding favours anticoagulant therapy in these patients (13, 15-18,42-43). However, DOACs are increasingly used. Indeed, results published by Naymagon et al. (2020) (35) showed, for the first time in a large group of patients, how DOACs could be a safe and beneficial treatment option for non-cirrhotic PVT. In this cohort (330 patients with non-cirrhotic PVT) treated with DOACs $(n=93$, of which $n=65$ with rivaroxaban) showed rates of complete radiographic resolution $(\mathrm{CRR})$ of PVT $(61 / 93=66 \%)$ and bleeding complications similarly when compared to patients under LWMH $(\mathrm{n}=70)$ but better than in patients under VKAs $(\mathrm{n}=108)$. Therefore, DOACs can be addressed as a safe and effective alternative to traditional anticoagulation in treating acute PVT in patients without cirrhosis, even though future prospective studies are needed.

\section{Anticoagulation in cirrhotic PVT}

Although PVT can be a common finding in patients with ACLD, the chance of a spontaneous recanalisation is not remote, occurring in up to $40 \%$ of the cases (2). Because of the risk of bleeding in these patients, the question is which patients might benefit from treatment and which anticoagulant treatment should be preferred.

In patients with stable cirrhosis who are potential candidates for LT or are currently on the waiting list for LT, anticoagulation should be initiated to treat PVT, mainly if it is of recent onset. Indeed, anticoagulation not only decreases PVT progression but also promotes recanalisation (28). In these patients, an occlusive thrombosis of PV (as per Sarin et al. (4)) should be considered as an indication to start treatment when practicable (1). Patients with a recent diagnosis of non-occlusive PVT (4) should undergo serial imaging every 3 months because of possible spontaneous recanalisation and start an anti-thrombotic treatment only if a progression is present (1). In all remaining cases, the decision for treatment should be individualised by balancing risks and benefits.

Data regarding anticoagulation in cirrhotic patients come from studies that were mostly carried out in patients with compensated disease and treated with traditional agents like LWMHs and VKAs. LMWHs are safe and effective in carefully selected patients but have limitations due to their monitoring (anti-Xa), renal dosing and subcutaneous administration, which may limit patient compliance $(30,44)$. VKAs are a low-cost oral alternative with a similar profile both for safety and efficacy but remain challenging due to recurring dose adjustments (INR monitoring) and possible diet interactions (30). The use of traditional anticoagulants is favoured in LT candidates (45), while their benefits are less clear outside this setting (9). However, starting anticoagulation within 6 months from the diagnosis of PVT has shown to be related to better recanalisation outcomes, with a success rate of $60 \%$ in patients with cirrhosis and PVT (46).

\section{Direct oral anticoagulants (DOACs) in cirrhosis}

DOACs have become a valuable alternative to replacing traditional anticoagulation with immediate anticoagulant effect and stable pharmacokinetics and pharmacodynamics. However, if compared to traditional anticoagulants, they are expensive and require strong compliance by patients and caution with severe acute or chronic kidney disease and impaired liver function (47-48). Their action can be reversed in the emergency setting by specific and expensive agents that sequester and neutralise the anticoagulant (e.g. idarucizumab for dabigatran, andexanet alfa for rivaroxaban and apixaban). However, appropriate studies investigating their use are lacking, and their provision is still expensive (49-51).

To date, experience with DOACs in the treatment of patients with cirrhosis has been limited to patients with a well-compensated disease (36,38-39,52-53). Besides, in vitro studies using plasma of patients with decompensated cirrhosis showed altered anticoagulant potency of DOACs (54-55). In a multicenter survey from the Vascular Liver Disease Interest Group Consortium (VALDIG) (39), 36 patients with cirrhosis (ChildPugh A and B) were treated with DOACs, mainly due to splanchnic vein thrombosis $(75 \%)$. Rivaroxaban, followed by dabigatran and apixaban, were the most commonly used drugs. All DOACs showed a favourable profile as to safety and efficacy over a median follow-up of 15 months. In a recent meta-analysis by Valeriani et al. (56), a large population $(n=1,475)$ of cirrhotic patients with splanchnic vein thrombosis showed improved vein recanalisation, reduced thrombosis progression and overall mortality under anticoagulation (including DOACs), and this without increasing the risk of major bleeding.

Based on the current knowledge, the use of DOACs in Child-Pugh C patients should be avoided for safety reasons (49) because clinical data in patients with advanced cirrhosis stages (Child-Pugh B and C) are scarce. Results from the CIRROXABAN study, which investigates rivaroxaban's effect on survival and development of complications of portal hypertension in patients with advanced cirrhosis, will provide more clarity on this topic (57).

\section{Thrombolysis and interventional vascular procedures for $P V T$}

Local catheter-directed thrombolysis can be performed via a percutaneous transhepatic, transjugular, or trans- 
splenic approach in patients with recent PVT. However, results available so far are based on small cohorts of patients and are associated with relevant morbidity and mortality. Therefore, local or systemic thrombolytic therapy should only be considered in selected cases of recent portal vein thrombosis (PVT) when intestinal ischemia persists despite anticoagulation (58-64).

Transjugular Intrahepatic Portosystemic Shunt (TIPS) is an effective treatment in patients who have neither responded to nor showed progression under first-line PVT treatment with anticoagulants. However, TIPS can be evaluated already at the time of diagnosis of PVT in patients who have contraindications to pharmacological anticoagulation or have additional indications to TIPS implantation for PH-related issues such as esophageal varices or ascites (1). In LT candidates, in particular, a chronic, extensive PVT possibly complicated by cavernous transformation could technically hinder a physiological anastomosis between the graft and the recipient PV. In such cases, a recanalisation through TIPS can potentially solve thrombosis and $\mathrm{PH}$ complications and is also a safe bridging option to transplantation (1, 65-67). Similarly, patients with chronic PVT and recurrent bleeding and/or refractory ascites can safely undergo TIPS implantation as an adjunctive treatment option $(50,65)$.

\section{Conclusions and prospects for future research}

The treatment of PVT is challenging. Although important results from recent studies improve our understanding of aetiology, natural history, and therapy options of PVT in both non-cirrhotic and cirrhotic settings, our experience is still limited, in particular with new anticoagulants and more invasive procedures.

Anticoagulation remains the first-choice therapeutic approach because it is generally safe, efficient and costeffective. However, the choice of anticoagulant needs to be individualised. LMWHs are the initial option, followed by VKAs or new DOACs according to the patient's characteristics. More invasive approaches (e.g. recanalisation techniques with or without TIPS) are useful options in selected cases.

Further data, particularly from prospective studies, are eagerly needed, and multicenter collaborative efforts are required to improve PVT current treatment.

\section{References}

1. NORTHUP PG, GARCIA-PAGAN JC, GARCIA-TSAO G, INTAGLIATA NM, SUPERINA RA, ROBERTS LN, et al. Vascular Liver Disorders, Portal Vein Thrombosis, and Procedural Bleeding in Patients With Liver Disease : 2020 Practice Guidance by the American Association for the Study of Liver Diseases. : 130.

2. INTAGLIATA NM, CALDWELL SH, TRIPODI A. Diagnosis, Development, and Treatment of Portal Vein Thrombosis in Patients With and Without Cirrhosis. Gastroenterology. 2019, 156(6) : 1582-1599.e1.

3. BOSCH J, NAVASA M, GARCIA-PAGÁN JC, DELACY AM, RODÉS J. Portal hypertension. Med. Clin. North Am. 1989 Jul, 73(4) : 931-53.

4. SARIN SK, PHILIPS CA, KAMATH PS, CHOUDHURY A, MARUYAMA H, NERY FG, et al. Toward a Comprehensive New Classification of Portal
Vein Thrombosis in Patients With Cirrhosis. Gastroenterology. 2016 Oct, 151(4) : 574-577.e3.

5. FACCIA M, AINORA ME, PONZIANI FR, RICCARDI L, GARCOVICH M, GASBARRINI A, et al. Portal vein thrombosis in cirrhosis : Why a wellknown complication is still matter of debate. World J. Gastroenterol. 2019 Aug 21, 25(31) : 4437-51.

6. AMITRANO L, GUARDASCIONE MA, BRANCACCIO V, MARGAGLIONE M, MANGUSO F, IANNACCONE L, et al. Risk factors and clinical presentation of portal vein thrombosis in patients with liver cirrhosis. J. Hepatol. 2004 May, 40(5) : 736-41.

7. FRANCOZ C, BELGHITI J, VILGRAIN V, SOMMACALE D, PARADIS $\mathrm{V}$, CONDAT B, et al. Splanchnic vein thrombosis in candidates for liver transplantation : usefulness of screening and anticoagulation. Gut. 2005 May, 54(5) : 691-7.

8. OGREN M, BERGQVIST D, BJÖRCK M, ACOSTA S, ERIKSSON H, STERNBY NH. Portal vein thrombosis : prevalence, patient characteristics and lifetime risk : a population study based on 23,796 consecutive autopsies. World J. Gastroenterol. 2006 Apr 7, 12(13) : 2115-9.

9. NERY F, CHEVRET S, CONDAT B, DE RAUCOURT E, BOUDAOUD L, RAUTOU P-E, et al. Causes and consequences of portal vein thrombosis in 1,243 patients with cirrhosis : results of a longitudinal study. Hepatol. Baltim. Md. $2015 \mathrm{Feb}$, 61(2) : 660-7.

10. MÄHRINGER-KUNZ A, STEINLE V, DÜBER C, WEINMANN A, KOCH $\mathrm{S}$, SCHMIDTMANN I, et al. Extent of portal vein tumour thrombosis in patients with hepatocellular carcinoma : The more, the worse? Liver Int. Off. J. Int. Assoc. Study Liver. 2019, 39(2) : 324-31.

11. CIAVARELLA A, GNOCCHI D, CUSTODERO C, LENATO GM, FIORE G, SABBÀ C, MAZZOCCA A. Translational insight into prothrombotic state and hypercoagulation in nonalcoholic fatty liver disease. Thromb. Res. 2021 Feb, $198:$ : 139-150.

12. VILLA E, CAMMÀ C, MARIETTA M, LUONGO M, CRITELLI R, COLOPI S, et al. Enoxaparin prevents portal vein thrombosis and liver decompensation in patients with advanced cirrhosis. Gastroenterology. 2012 Nov, 143(5) : 1253-1260.e4.

13. PLESSIER A, DARWISH-MURAD S, HERNANDEZ-GUERRA M, CONSIGNY Y, FABRIS F, TREBICKA J, et al. Acute portal vein thrombosis unrelated to cirrhosis : a prospective multicenter follow-up study. Hepatol. Baltim. Md. 2010 Jan, 51(1) : 210-8.

14. COREMANS L, STRUBBE B, PEETERS H. Venous thromboembolism in patients with inflammatory bowel disease : review of literature and practical algorithms. Acta Gastroenterol. Belg. 2021 Jan-Mar, 84(1) : 79-85.

15. NORONHA FERREIRA C, SEIJO S, PLESSIER A, SILVA-JUNIOR G, TURON F, RAUTOU P-E, et al. Natural history and management of esophagogastric varices in chronic noncirrhotic, nontumoral portal vein thrombosis. Hepatol. Baltim. Md. 2016 May, 63(5) : 1640-50.

16. SPAANDER MCW, HOEKSTRA J, HANSEN BE, VAN BUUREN HR, LEEBEEK FWG, JANSSEN HLA. Anticoagulant therapy in patients with non-cirrhotic portal vein thrombosis : effect on new thrombotic events and gastrointestinal bleeding. J. Thromb. Haemost. JTH. 2013 Mar, 11(3) : 452-9.

17. AMITRANO L, GUARDASCIONE MA, SCAGLIONE M, PEZZULLO L, SANGIULIANO N, ARMELliNO MF, et al. Prognostic factors in noncirrhotic patients with splanchnic vein thromboses. Am. J. Gastroenterol. 2007 Nov, 102(11) : 2464-70

18. ORR DW, HARRISON PM, DEVLIN J, KARANI JB, KANE PA, HEATON ND, et al. Chronic mesenteric venous thrombosis : evaluation and determinants of survival during long-term follow-up. Clin. Gastroenterol. Hepatol. Off. Clin. Pract. J. Am. Gastroenterol. Assoc. 2007 Jan, 5(1) : 80-6.

19. HERNÁNDEZ-GEA V, DE GOTTARDI A, LEEBEEK FWG, RAUTOU P-E, SALEM R, GARCIA-PAGAN JC. Current knowledge in pathophysiology and management of Budd-Chiari syndrome and non-cirrhotic non-tumoral splanchnic vein thrombosis. J. Hepatol. 2019 Jul, 71(1) : 175-99.

20. LISMAN T, PORTE RJ. Pathogenesis, prevention, and management of bleeding and thrombosis in patients with liver diseases. Res. Pract. Thromb. Haemost. 2017 Oct, 1(2) : 150-61.

21. QI X, GUO X, YOSHIDA EM, MÉNDEZ-SÁNCHEZ N, DE STEFANO $\mathrm{V}$, TACKE F, et al. Transient portal vein thrombosis in liver cirrhosis. BMC Med. 2018 Jun 5, 16(1) : 83.

22. TREBICKA J, STRASSBURG CP. Etiology and Complications of Portal Vein Thrombosis. Viszeralmedizin. 2014 Dec, 30(6) : 375-80.

23. LA MURA V, BRAHAM S, TOSETTI G, BRANCHI F, BITTO N, MOIA M, et al. Harmful and Beneficial Effects of Anticoagulants in Patients With Cirrhosis and Portal Vein Thrombosis. Clin. Gastroenterol. Hepatol. Off. Clin. Pract. J. Am. Gastroenterol. Assoc. 2018, 16(7) : 1146-1152.e4.

24. HIBI T, NISHIDA S, LEVI DM, SELVAGGI G, TEKIN A, FAN J, et al. When and why portal vein thrombosis matters in liver transplantation: a critical audit of 174 cases. Ann. Surg. 2014 Apr, 259(4) : 760-6. 
25. CONZEN KD, POMFRET EA. Liver transplant in patients with portal vein thrombosis : Medical and surgical requirements. Liver Transplant. Off. Publ. Am. Assoc. Study Liver Dis. Int. Liver Transplant. Soc. 2017, 23(S1) : S59-63.

26. ENGLESBE MJ, KUBUS J, MUHAMMAD W, SONNENDAY CJ, WELLING T, PUNCH JD, et al. Portal vein thrombosis and survival in patients with cirrhosis. Liver Transplant. Off. Publ. Am. Assoc. Study Liver Dis. Int. Liver Transplant. Soc. 2010 Jan, 16(1) : 83-90.

27. ENGLESBE MJ, SCHAUBEL DE, CAI S, GUIDINGER MK, MERION RM. Portal vein thrombosis and liver transplant survival benefit. Liver Transplant. Off. Publ. Am. Assoc. Study Liver Dis. Int. Liver Transplant. Soc. 2010 Aug, 16(8) : 999-1005.

28. TURNES J, GARCÍA-PAGÁN JC, GONZÁLEZ M, ARACIL C, CALLEJA JL, RIPOLL C, et al. Portal hypertension-related complications after acute portal vein thrombosis : impact of early anticoagulation. Clin. Gastroenterol. Hepatol. Off. Clin. Pract. J. Am. Gastroenterol. Assoc. 2008 Dec, 6(12) : 1412-7.

29. AMITRANO L, GUARDASCIONE MA, MENCHISE A, MARTINO R, SCAGLIONE M, GIOVINE S, et al. Safety and efficacy of anticoagulation therapy with low molecular weight heparin for portal vein thrombosis in patients with liver cirrhosis. J. Clin. Gastroenterol. 2010 Jul, 44(6) : 448-51.

30. LOFFREDO L, PASTORI D, FARCOMENI A, VIOLI F. Effects of Anticoagulants in Patients With Cirrhosis and Portal Vein Thrombosis : A Systematic Review and Meta-analysis. Gastroenterology. 2017, 153(2) : 480487.e1.

31. NERY F, VALADARES D, MORAIS S, GOMES MT, DE GOTTARDI A. Efficacy and Safety of Direct-Acting Oral Anticoagulants Use in Acute Portal Vein Thrombosis Unrelated to Cirrhosis. Gastroenterol. Res. 2017 Apr, 10(2) : 141-3.

32. AGNELli G, BULLER HR, COHEN A, CURTO M, GALLUS AS, JOHNSON M, et al. Apixaban for extended treatment of venous thromboembolism. N. Engl. J. Med. 2013 Feb 21, 368(8) : 699-708.

33. JANCZAK DT, MIMIER MK, MCBANE RD, KAMATH PS, SIMMONS BS, BOTT-KITSLAAR DM, et al. Rivaroxaban and Apixaban for Initial Treatment of Acute Venous Thromboembolism of Atypical Location. Mayo Clin. Proc. 2018 Jan, 93(1) : 40-7.

34. LI A, GARCIA DA, LYMAN GH, CARRIER M. Direct oral anticoagulant (DOAC) versus low-molecular-weight heparin (LMWH) for treatment of cancer associated thrombosis (CAT) : A systematic review and meta-analysis. Thromb. Res. 2019 Jan, 173 : 158-63.

35. NAYMAGON L, TREMBLAY D, ZUBIZARRETA N, MOSHIER E, TROY $\mathrm{K}$, SCHIANO T, et al. The efficacy and safety of direct oral anticoagulants in noncirrhotic portal vein thrombosis. Blood. Adv. 2020 25, 4(4) : 655-66.

36. INTAGLIATA NM, HENRY ZH, MAITLAND H, SHAH NL, ARGO CK, NORTHUP PG, et al. Direct Oral Anticoagulants in Cirrhosis Patients Pose Similar Risks of Bleeding When Compared to Traditional Anticoagulation. Dig. Dis. Sci. 2016 Jun, 61(6) : 1721-7.

37. INTAGLIATA NM, MAITLAND H, PELLITIER S, CALDWELL SH. Reversal of direct oral anticoagulants for liver transplantation in cirrhosis : A step forward. Liver Transplant. Off. Publ. Am. Assoc. Study Liver Dis. Int Liver Transplant. Soc. 2017 Mar, 23(3) : 396-7.

38. HUM J, SHATZEL JJ, JOU JH, DELOUGHERY TG. The efficacy and safety of direct oral anticoagulants vs traditional anticoagulants in cirrhosis. Eur. $J$. Haematol. 2017 Apr, 98(4) : 393-7.

39. DE GOTTARDI A, TREBICKA J, KLINGER C, PLESSIER A, SEIJO S, TERZIROLI B, et al. Antithrombotic treatment with direct-acting oral anticoagulants in patients with splanchnic vein thrombosis and cirrhosis. Liver Int. Off. J. Int. Assoc. Study Liver. 2017 May, 37(5) : 694-9.

40. NAGAOKI Y, AIKATA H, DAIJYO K, TERAOKA Y, SHINOHARA F, NAKAMURA Y, et al. Efficacy and safety of edoxaban for treatment of portal vein thrombosis following danaparoid sodium in patients with liver cirrhosis. Hepatol. Res. Off. J. Jpn. Soc. Hepatol. 2018 Jan, 48(1) : 51-8.

41. DE GOTTARDI A, GARCIA-PAGAN JC, VALDIG Investigators. The anticoagulant efficacy of rivaroxaban may be attenuated in cirrhotic patients. Liver Int. 2017 Aug, 37(8) : 1252.

42. CONDAT B, PESSIONE F, HILLAIRE S, DENNINGER MH, GUILLIN MC, POLIQUIN M, et al. Current outcome of portal vein thrombosis in adults : risk and benefit of anticoagulant therapy. Gastroenterology. 2001 Feb, 120(2) : 490-7.

43. PRIYANKA P, KUPEC JT, KRAFFT M, SHAH NA, REYNOLDS GJ. Newer Oral Anticoagulants in the Treatment of Acute Portal Vein Thrombosis in Patients with and without Cirrhosis. Int J Hepatol. 2018, $2018: 8432781$.

44. O'LEARY JG, GREENBERG CS, PATTON HM, CALDWELL SH. AGA Clinical Practice Update : Coagulation in Cirrhosis. Gastroenterology. 2019 Jul, 157(1) : 34-43.e1

45. NORTHUP P, REUTEMANN B. Management of Coagulation and Anticoagulation in Liver Transplantation Candidates. Liver Transplant. Off. Publ. Am. Assoc. Study Liver Dis. Int. Liver Transplant. Soc. 2018 Aug, 24(8) : 1119-32.
46. DELGADO MG, SEIJO S, YEPES I, ACHÉCAR L, CATALINA MV, GARCÍA-CRIADO A, et al. Efficacy and safety of anticoagulation on patients with cirrhosis and portal vein thrombosis. Clin. Gastroenterol. Hepatol. Off. Clin. Pract. J. Am. Gastroenterol. Assoc. 2012 Jul, 10(7) : 776-83.

47. BAUER KA. Pros and cons of new oral anticoagulants. Hematol. Am. Soc. Hematol. Educ. Program. 2013, 2013 : 464-70.

48. SARTORI MT, PRANDONI P. How to effectively manage the event of bleeding complications when using anticoagulants. Expert Rev. Hematol. 2016 Jan, 9(1) : 37-50.

49. LIP GYH, LANE DA. Matching the NOAC to the Patient: Remember the Modifiable Bleeding Risk Factors. J. Am. Coll. Cardiol. 2015 Dec 1, 66(21) : 2282-4.

50. LIP GYH, BANERJEE A, BORIANI G, CHIANG CE, FARGO R, FREEDMAN B, et al. Antithrombotic Therapy for Atrial Fibrillation: CHEST Guideline and Expert Panel Report. Chest. 2018 Nov, 154(5) : 1121201.

51. SAMUELSON BT, CUKER A. Measurement and reversal of the direct oral anticoagulants. Blood Rev. 2017 Jan, 31(1) : 77-84.

52. INTAGLIATA NM, MAITLAND H, NORTHUP PG, CALDWELL SH. Treating thrombosis in cirrhosis patients with new oral agents : ready or not? Hepatol. Baltim. Md. $2015 \mathrm{Feb}, 61(2)$ : 738-9.

53. SERPER M, WEINBERG EM, COHEN JB, REESE PP, TADDEI TH, KAPLAN DE. Mortality and Hepatic Decompensation in Patients With Cirrhosis and Atrial Fibrillation Treated With Anticoagulation. Hepatol. 2020 Apr, 73 : 219-232

54. POTZE W, ARSHAD F, ADELMEIJER J, BLOKZIJL H, VAN DEN BERG AP, MEIJERS JCM, et al. Differential in vitro inhibition of thrombin generation by anticoagulant drugs in plasma from patients with cirrhosis. PloS One. 2014, 9(2) : e88390.

55. POTZE W, ADELMEIJER J, LISMAN T. Decreased in vitro anticoagulant potency of Rivaroxaban and Apixaban in plasma from patients with cirrhosis. Hepatol. Baltim. Md. 2015 Apr, 61(4) : 1435-6.

56. VALERIANI E, DI NISIO M, RIVAN, COHEN O, PORRECA E, SENZOLO $\mathrm{M}$, et al. Anticoagulant Treatment for Splanchnic Vein Thrombosis in Live Cirrhosis : A Systematic Review and Meta-Analysis. Thromb. Haemost. 2021 Feb $1: \mathbf{1 0} .1055 / \mathrm{s}-0040-1722192$.

57. Multicenter Prospective Randomized Trial of the Effect of Rivaroxaban on Survival and Development of Complications of Portal Hypertension in Patients With Cirrhosis : https: //clinicaltrials.gov/ct2/show/NCT02643212

58. THORNBURG B, DESAI K, HICKEY R, HOHLASTOS E, KULIK L, GANGER D, et al. Pretransplantation Portal Vein Recanalization and Transjugular Intrahepatic Portosystemic Shunt Creation for Chronic Portal Vein Thrombosis : Final Analysis of a 61-Patient Cohort. J. Vasc. Interv. Radiol JVIR. 2017 Dec, 28(12) : 1714-1721.e2.

59. SALEM R, VOUCHE M, BAKER T, HERRERO JI, CAICEDO JC, FRYER $\mathrm{J}$, et al. Pretransplant Portal Vein Recanalization-Transjugular Intrahepatic Portosystemic Shunt in Patients With Complete Obliterative Portal Vein Thrombosis. Transplantation. 2015 Nov, 99(11) : 2347-55.

60. ROSENQVIST K, ERIKSSON L-G, RORSMAN F, SANGFELT P, NYMAN R. Endovascular treatment of acute and chronic portal vein thrombosis in patients with cirrhotic and non-cirrhotic liver. Acta Radiol. Stockh. Swed. 1987. 2016 May, 57(5) : 572-9

61. CAO G, KO G-Y, SUNG K-B, YOON H-K, GWON DI, KIM J-H. Treatment of postoperative main portal vein and superior mesenteric vein thrombosis with balloon angioplasty and/or stent placement. Acta Radiol. Stockh. Swed. 1987. 2013 Jun, 54(5) : 526-32.

62. SMALBERG JH, SPAANDER MVMCW, JIE K-SG, PATTYNAMA PMT, VAN BUUREN HR, VAN DEN BERG B, et al. Risks and benefits of transcatheter thrombolytic therapy in patients with splanchnic venous thrombosis. Thromb. Haemost. 2008 Dec, 100(6) : 1084-8.

63. LIU K, LI W-D, DU X-L, LI C-L, LI X-Q. Comparison of Systemic Thrombolysis Versus Indirect Thrombolysis via the Superior Mesenteric Artery in Patients with Acute Portal Vein Thrombosis. Ann. Vasc. Surg. 2017 Feb, 39 : 264-9.

64. WOLTER K, DECKER G, KUETTING D, TREBICKA J, MANEKELLER S, MEYER C, et al. Interventional Treatment of Acute Portal Vein Thrombosis. ROFO Fortschr. Geb. Rontgenstr. Nuklearmed. 2018, 190(8) : 740-6.

65. RODRIGUES SG, SIXT S, ABRALDES JG, DE GOTTARDI A, KLINGER $\mathrm{C}$, BOSCH J, et al. Systematic review with meta-analysis: portal vein recanalisation and transjugular intrahepatic portosystemic shunt for portal vein thrombosis. Aliment. Pharmacol. Ther. 2019, 49(1) : 20-30.

66. THORNBURG B, DESAI K, HICKEY R, KULIK L, GANGER D, BAKER T, et al. Portal Vein Recanalization and Transjugular Intrahepatic Portosystemic Shunt Creation for Chronic Portal Vein Thrombosis : Technical Considerations. Tech. Vasc. Interv. Radiol. 2016 Mar, 19(1) : 52-60.

67. VALENTIN N, KORRAPATI P, CONSTANTINO J, YOUNG A, WEISBERG I. The role of transjugular intrahepatic portosystemic shunt in the management of portal vein thrombosis: a systematic review and metaanalysis. Eur. J. Gastroenterol. Hepatol. 2018 Oct, 30(10) : 1187-93. 